Int. J. Electrochem. Sci., 13 (2018) $2887-2910$

International Journal of

ELECTROCHEMICAL

SCIENCE

WWw.electrochemsci.org

\title{
Synthesis and Characterization of Nanocomposite-Based Heteropolyacid, and its Catalytic, Photocatalytic and Electrochemical Performances
}

\author{
H. Salavati ${ }^{1, *}$, A. Teimouri ${ }^{1}$, S. Kazemi ${ }^{2}$ \\ ${ }^{1}$ Chemistry Department, Payame Noor University, 19395-3697, Tehran, Iran \\ ${ }^{2}$ Department of Chemistry, Faculty of Science, University of Birjand, P. O. Box 97175-615, Birjand, \\ Iran. \\ *E-mail: hosseinsalavati@pnu.ac.ir
}

doi: $10.20964 / 2018.03 .21$

Received: 29 August 2017 / Accepted: 25 December 2017 / Published: 5 February 2018

This work reports the synthesis and characterization as well as catalytic, photocatalytic and electrochemical performances of a novel supported catalyst based on $\mathrm{H}_{5} \mathrm{PMo}_{10} \mathrm{~V}_{2} \mathrm{O}_{40}$ Keggin type polyoxometalate (PMoV) immobilized on melamine grafted graphene oxide (Mel-GO). The supported catalyst (PMoV@Mel-GO) was characterized by X-ray diffraction spectroscopy (XRD), field emission scanning electron microscopy (FESEM), furrier transforms infrared spectroscopy (FT-IR), cyclic voltammetry $(\mathrm{CV})$ and UV-vis diffuse reflectance spectroscopy (UV-DRS). Electrochemical characterizations revealed that modified graphene oxide nano-sheets have excellent photocatalytic activity towards electron transfer. Electrochemical impedance spectroscopy (EIS) and cyclic voltammetry $(\mathrm{CV})$ spectroscopy confirmed the role of Keggin type polyoxometalate in charge transfer and electron transfer changes. The electroactive surface areas of the pure CPE and catalyst/CPE were appraised by CV technique confirming that for supported catalyst, modified electrode is approximately greater than that for pure CPE. For the optimization of main factors in photocatalytic activity, a statistical method called response surface methodology (RSM) based on the central composite design (CCD) was used to economize on the number of experiments and their meaningful interpretations. The supported catalyst showed high photocatalytic activity and reusability in the degradation of methylene blue (denoted as MB) as pollutant. Optimization results for initial dye concentration $20 \mathrm{mg} / \mathrm{L}$ showed that maximum degradation efficiency, $97.71 \%$, was achieved at optimum conditions, catalyst amount $17.5 \mathrm{mg}$ and $\mathrm{pH}=6.1$ for reaction time $66 \mathrm{~min}$. In addition, the catalyst showed high activity in the desulfurization of dibenzothiophene (abbreviated as DBT) to dibenzothiophene sulfone product (denoted as $\mathrm{DBTO}_{2}$ ) using formal batch method with $98.2 \%$ conversion at $50^{\circ} \mathrm{C}$. In addition, the sulfone product was characterized by NMR, FT-IR, Mass spectroscopy and GC analysis. The optimal conditions for conversion of DBT were found to be; $\mathrm{H}_{2} \mathrm{O}_{2} / \mathrm{DBT} 3: 1$, reaction temperature $50^{\circ} \mathrm{C}$ and reaction time $120 \mathrm{~min}$ for $0.05 \mathrm{~g}$ catalyst amount.

Keywords: Cyclic Voltammetry, Electrochemical, Graphene oxide, Heteropolyacid, Photocatalytic 


\section{FULL TEXT}

(C) 2018 The Authors. Published by ESG (www.electrochemsci.org). This article is an open access article distributed under the terms and conditions of the Creative Commons Attribution license (http://creativecommons.org/licenses/by/4.0/). 